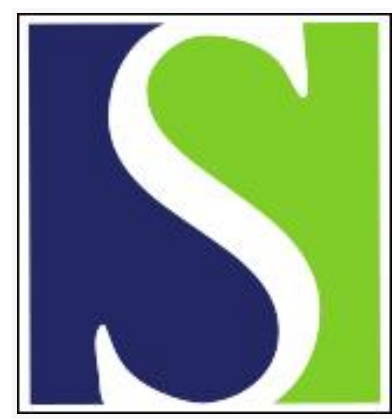

Scand J Work Environ Health 1999;25(2):115-124

https://doi.org/10.5271/sjweh.413

Issue date: Apr 1999

Agreement between symptom surveys, physical examination procedures and electrodiagnostic findings for the carpal tunnel syndrome

by Homan MM, Franzblau A, Werner RA, Albers JW, Armstrong TJ, Bromberg MB

The following article refers to this text: 2011;37(4):298-306

Key terms: carpal compression test; discomfort survey; hand diagram; kappa coefficient; nerve conduction testing; Phalen's test; surveillance; Tinel's test

This article in PubMed: www.ncbi.nlm.nih.gov/pubmed/10360466

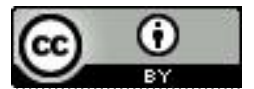




\title{
Agreement between symptom surveys, physical examination procedures and electrodiagnostic findings for the carpal tunnel syndrome
}

\author{
by Michelle M Homan, MS, ${ }^{1,2}$ Alfred Franzblau, MD, ${ }^{1,2}$ Robert A Werner, MD, 1,2,3 James W Albers, MD,1,4 \\ Thomas J Armstrong, PhD, ${ }^{1,2}$ Mark B Bromberg, MD
}

\begin{abstract}
Homan MM, Franzblau A, Werner RA, Albers JW, Armstrong TJ, Bromberg MB. Agreement between symptom surveys, physical examination procedures and electrodiagnostic findings for the carpal tunnel syndrome. Scand $J$ Work Environ Health 1999;25(2):115-124.

Objectives The goal of this study was to evaluate the concordance between various clinical screening procedures for carpal tunnel syndrome.

Methods The subject population consisted of 824 workers from 6 facilities. The evaluated procedures included bilateral sensory nerve conduction testing, physical examinations, and symptom surveys, including hand diagrams. The agreement between the outcomes of various combinations of these procedures was assessed by determining the kappa coefficient.

Results There was relatively poor overlap between the reported symptoms, the physical examination findings, and the electrodiagnostic results consistent with carpal tunnel syndrome. Overall, only 23 out of 449 subjects (5\%) with at least 1 positive finding met all 3 criteria (symptoms, physical examination findings, and electrophysiological results consistent with carpal tunnel syndrome) for the dominant hand. The screening procedures showed poor or no agreement with kappa values ranging between 0.00 and 0.18 for all the case definitions evaluated for carpal tunnel syndrome.

Conclusions The poor overlap between the various screening procedures warns against the use of electrodiagnostic findings alone without the symptom presentation being considered. The results of this study also point to a need for the further development and evaluation of methods for detecting carpal tunnel syndrome.
\end{abstract}

Key terms carpal compression test, discomfort survey, hand diagrams, kappa coefficient, nerve conduction testing, Phalen's test, surveillance, Tinel's test

In the past 10 to 15 years, upper extremity musculoskeletal disorders, and carpal tunnel syndrome (CTS) in particular, have emerged as leading work-related health concerns in the United States $(1,2)$. For a better understanding and potential control of the problem, workplace surveillance programs and further epidemiologic research have been recommended $(3,4)$. The objectives of workplace surveillance for CTS are to assist in the monitoring of trends, the identification of risk factors, the targeting of problem jobs for intervention, and the evaluation of intervention and control programs (5).
Surveillance may also permit the identification of people with mild symptoms, allow for early treatment and, in theory, limit the progression of the underlying disease severity (3). The overall goal of epidemiologic research is to understand the exposure-response relationship between ergonomic risk factors and carpal tunnel syndrome better. In addition, such research provides the scientific basis for workplace surveillance and control of such disorders (5). The outcomes of workplace surveillance and epidemiologic research are, however, significantly affected by the validity of the screening techniques employed.

Department of Environmental and Industrial Health, University of Michigan School of Public Health, Ann Arbor, Michigan, United States.

2 Center of Ergonomics, University of Michigan School of Engineering, Ann Arbor, Michigan, United States.

3 Physical Medicine and Rehabilitation, Ann Arbor Veterans' Administration Hospital, Ann Arbor, and Department of Physical Medicine and Rehabilitation, University of Michigan School of Medicine, Ann Arbor, Michigan, United States.

4 Department of Neurology, University of Michigan School of Medicine, Ann Arbor, Michigan, United States.

5 Department of Neurology, University of Utah School of Medicine, Salt Lake City, Utah, United States.

Reprint requests to: Dr A Franzblau, Department of Environmental and Industrial Health, University of Michigan School of Public Health, 1420 Washington Heights, Ann Arbor, MI 48109-2029, USA. 
Several tools and procedures have been employed in the surveillance or epidemiologic investigation of carpal tunnel syndrome. They include symptom surveys $(6-$ $13)$, a variety of physical examination procedures $(8,9$, $11,12,14-17)$, and electrodiagnostic testing (17-19). Symptom surveys have traditionally been utilized to gather information on the body location, frequency, and magnitude of musculoskeletal symptoms among workers. These surveys often contain additional questions pertaining to the demographics, medical history, work history, and avocational activities of the worker. The physical examination procedures traditionally used in the evaluation of CTS screening involve inspection, palpation, and maneuvers to determine the passive, active, and resisted range of motion. Additional maneuvers, such as Phalen's and Tinel's tests, are frequently included to determine the presence and distribution of symptoms consistent with CTS $(3,8)$.

The development of screening instruments and procedures is particularly challenging with regard to CTS for several reasons. Electrodiagnostic testing, while considered to be the most accurate procedure for detecting CTS, is often not recommended for surveillance purposes due to the additional commitment in time and resources necessary for its conduction $(17,19)$. In addition, currently, there is no universally endorsed set of criteria for the diagnosis of CTS. Furthermore, in many studies, screening techniques for CTS have traditionally been plagued by low sensitivity, low specificity, and positive predictive values $(17,19,20-25)$.

This report summarizes and combines the results of 6 cross-sectional medical surveys of active workers. The main goal of this study was to determine the concordance between various procedures used in the diagnosis of CTS. The procedures examined in this study include self-administered symptom surveys including hand diagrams, physical examination procedures, and sensory nerve conduction testing. The agreement between the procedures was assessed through the determination of the kappa coefficient. Based on this and other analyses, recommendations are included about which techniques are the most useful for purposes of workplace surveillance or the epidemiologic study of CTS.

\section{Subjects and methods}

\section{Subjects}

The subjects were recruited from 6 independent companies representing manufacturing, office, and computerrelated jobs. Prior to participation, all the subjects were made aware of the study protocol, and each provided a written informed consent which had been approved by the University of Michigan Institutional Review Board. All the survey procedures were performed on "company time" during each worker's regular shift, except at study site 3 . The management at site 3 required that survey evaluations be performed before or after the workers' shifts and without pay. Each participant received a confidential written summary of his or her medical survey results (including electrodiagnostic results), an interpretation of the results, and recommendations for medical follow-up, if warranted. Personally identifiable results were not provided to employers.

The data presented in this study were collected between June 1993 and June 1996. The type of industry, number of subjects recruited, and participation rates are listed in table 1. Four of the sites (sites 1, 2, 3 and 4) represented jobs from the manufacturing sector, while sites 5 and 6 involved office or computer-related work. The total number of participating subjects across the 6 study sites was 824 out of 1103 eligible (75\%), with a mean job tenure of 8.9 (SD 9.1) years. The overall gender distribution of the subjects was $61 \%$ female, while the mean age was 37.9 (SD 10.7) years. The participation rates were generally high (74\% to $88 \%$ for sites 1 , $2,4,5$, and 6 ), except for site 3 . The participation rate at site 3 was lower than at the other sites because evaluations were not permitted during the regular workshift. The mean age of the study participants was relatively consistent across sites except for site 4 , for which the mean age was higher at 44.5 years. The workers in the study represented a wide range of jobs typically found at manufacturing and clerical sites. The jobs ranged from loading machines and monitoring their operations to highly repetitive hand transfer and assembly operations. The office jobs ranged between incidental use of

Table 1. Demographic characteristics of the study participants.

\begin{tabular}{|c|c|c|c|c|c|c|c|c|c|}
\hline \multirow[t]{2}{*}{ Study site } & \multirow[t]{2}{*}{$\begin{array}{c}\text { Eligible } \\
(\mathbb{N})\end{array}$} & \multicolumn{2}{|c|}{ Participants } & \multicolumn{2}{|c|}{$\begin{array}{c}\text { Age } \\
\text { (years) }\end{array}$} & \multicolumn{2}{|c|}{ Men } & \multicolumn{2}{|c|}{$\begin{array}{l}\text { Right-hand } \\
\text { dominance }\end{array}$} \\
\hline & & N & $\%$ & Mean & $\mathrm{SD}$ & N & $\%$ & N & $\%$ \\
\hline 1. Office furniture manufacturer & 98 & 86 & 87.8 & 37.1 & 9.0 & 55 & 64.0 & 77 & 89.5 \\
\hline 2. Industrial container manufacturer & 90 & 77 & 85.6 & 37.9 & 9.5 & 56 & 72.7 & 64 & 83.1 \\
\hline 3. Auto components manufacturer & 166 & 75 & 45.2 & 37.1 & 11.2 & 20 & 27.0 & 70 & 93.3 \\
\hline 4. Spark plug manufacturer & 263 & 202 & 76.8 & 44.5 & 10.2 & 103 & 51.0 & 186 & 92.1 \\
\hline 5. Insurance claims processing center & 221 & 164 & 74.2 & 35.2 & 9.6 & 22 & 13.4 & 146 & 89.0 \\
\hline 6. Data processing center & 265 & 220 & 83 & 34.5 & 10.1 & 63 & 28.6 & 195 & 88.6 \\
\hline Total & 1103 & 824 & 74.7 & 37.9 & 10.7 & 319 & 38.7 & 738 & 89.6 \\
\hline
\end{tabular}


keyboards and medium-to-high hand activity associated with data processing.

\section{Methods}

The medical survey was uniform at all the study sites, and it included ulnar and median sensory nerve conduction studies on both wrists, completion of a self-administered questionnaire with hand diagrams, and a physical examination specific to the upper extremities. Members of the field study teams were masked to data collected by other study team members or via the questionnaire and to the electrodiagnostic test results.

Electrodiagnostic testing. Limited sensory nerve conduction studies were conducted at the wrist by physicians certified in electrodiagnostic medicine or technicians under their direct supervision. These studies were performed using percutaneous supramaximal stimulus with surface recordings and fixed distances $(14 \mathrm{~cm}$, antidromic stimulation). Sensory nerve action potential amplitude, onset latency, and peak latency were measured for the median and ulnar nerves of both hands (digits 2 and 5 ). For the purposes of this analysis, only the peak latencies were included in the analysis. A total of 824 subjects had the dominant hand tested, and 822 had the nondominant hand tested, representing a total of 1646 hands.

The midpalm temperature of both hands was monitored during the electrodiagnostic testing. The hand was warmed if the initial temperature was below $32^{\circ} \mathrm{C}$. The hand temperatures still ranged, however, between 29.0 and $36.2^{\circ} \mathrm{C}$ (mean $33.3^{\circ} \mathrm{C}$ ) for the dominant hands and between 29.0 and $36.0^{\circ} \mathrm{C}$ (mean $33.2^{\circ} \mathrm{C}$ ) for the nondominant hands. The influence of hand temperature on the absolute electrophysiological results is well known (26). In this study, however, relative electrophysiological findings (the difference between the ipsilateral median and ulnar sensory peak latencies) were examined rather than absolute values. A simple linear regression of hand temperature data collected for this study versus the difference between median and ulnar sensory peak latencies showed no significant association for the dominant hands $\left(\mathrm{r}^{2}=0.0012, \mathrm{P}=0.324\right)$ and a borderline relationship with very low explained variance for the nondominant hands $\left(r^{2}=0.0046, P=0.056\right)$. As a result, the relative latency differences were not corrected for hand temperature in the analyses.

Focal median nerve impairment, or median mononeuropathy (MM), was defined on a relative basis. This metric, which relies on the difference between the peak sensory latencies in the median versus ulnar nerve, provides a means to control for such factors as age, hand temperature, and the presence of systemic conditions which can influence the outcomes of nerve conduction testing. In addition, median mononeuropathy has been found be a highly stable and reliable measure (27). Two separate criteria were used to define median mononeuropathy at the wrist: a difference of $\geq 0.5$ milliseconds between the median and ulnar sensory peak latencies in the same wrist (MM-0.5) and a difference of $\geq 0.8$ milliseconds between the median and ulnar sensory peak latencies in the same wrist (MM-0.8). The 0.5-millisecond cutoff is a standard electrodiagnostic criterion for confirming median mononeuropathy at the wrist (28). A higher cutoff point $(0.8 \mathrm{~ms})$ was also chosen to indicate a more severe level of median nerve impairment.

\section{Self-administered symptom surveys and hand diagrams.}

The self-administered questionnaire collected a variety of information on demographics, work history, prior health conditions, current symptoms of the upper extremities, and psychosocial variables. Data on prior health conditions and psychosocial observations were not included in the analyses. The test-retest reliability of this questionnaire has been demonstrated to be good to excellent for industrial and office worker populations (13, 27). Two separate questions were analyzed with regard to the temporal aspects of the subject's symptomatology. The first question asked subjects to report recurring or persistent symptoms that occurred up to 1 year prior to the survey. The second asked subjects to report and rate the current level of discomfort they were experiencing.

With regard to recurring or persistent symptoms, the subjects were instructed to report a symptom if the following conditions were met: the symptom occurred on $\geq 3$ separate occasions in the 12 months preceding the survey, or the symptom lasted more than 1 week in the 12 months preceding the survey. The questionnaire gathered information on 9 separate symptoms (burning, stiffness, pain, cramping, tightness, aching, soreness, tingling and numbness) across 15 upper extremity sites (neck, right shoulder, left shoulder, right upper arm, left upper arm, right elbow, left elbow, right forearm, left forearm, right wrist, left wrist, right hand, left hand, right fingers, and left fingers). Since carpal tunnel syndrome was the outcome of interest in this study, only data suggestive of the disorder were used in the subsequent analyses. This included symptoms of numbness, tingling, burning or pain in the wrist, hands or fingers.

The questionnaire also asked subjects to rate their current level of discomfort in all of the upper-extremity sites on a 10 -centimeter visual analogue scale. The verbal anchor points for the scales were "no discomfort" (equal to 0) and "worst discomfort imaginable" (equal to 10). For the purposes of this analysis, symptoms were considered present if the discomfort rating was $\geq 0.9$ for the dominant hand and $\geq 0.7$ for the nondominant hand. These cutoff points represent the 25 th percentile of current discomfort in the wrist, hands, or fingers for the visual analogue scale. A higher cutoff point representing the 
50 th percentile of current discomfort (2.1 and 2.0 for the dominant and nondominant hands, respectively) was also analyzed. For purposes of brevity, only results from using the lower cutoff point (25th percentile of the discomfort rating) have been included in this report.

The subjects were also queried about nocturnal symptoms by instructing them to report whether their symptoms had ever awakened them. Previous studies suggest that the inclusion of nocturnal symptoms may increase the positive predictive value without substantially compromising sensitivity when CTS is being screened for $(18,19)$.

The subjects also completed hand diagrams as previously described (29), as adapted from Katz $(6,7)$. They were instructed to shade in affected areas if the following conditions were met: (i) numbness, tingling, burning or pain in the wrists, hands or fingers and (ii) any of these symptoms occurring on $\geq 3$ separate episodes or 1 episode lasting more than 1 week in the 12 months preceding the survey. The hand diagrams were classified into 4 categories with respect to symptom distributions consistent with CTS, including classic, probable, possible, and unlikely.

In this analysis, symptoms consistent with CTS were defined in several ways using different combinations of the symptom survey results, nocturnal observations, and hand diagram scores. The CTS symptom definitions used in this analysis are defined in table 2.

Physical examinations. The protocols used during the physical examination were adapted from the reference Evaluation of Upper Extremity and Low Back Cumulative Trauma Disorders: a Screening Manual (30). The procedures included in this analysis were Phalen's test (14), Tinel's test (15), the carpal canal compression test (16), and the 2-point discrimination test. A 3-point anesthesiometer was used for the 2-point discrimination test. The test was considered normal if the subjects could perceive 2 points spaced 4 millimeters apart on the tip of the index finger. In the analysis, the physical examination results were considered consistent with CTS if at least 1 of the 4 tests was found to be abnormal.

Statistical analyses. Data were collected on the right and left hands of all the subjects and later transformed to adjust for hand dominance. The data were analyzed for each hand separately, as opposed to combining both hands into one analysis, to ensure the independence of each observation. The statistical package used in the analysis was STATA, version 5 (31). Agreement between procedures was evaluated by calculation of the kappa coefficient. Kappa values are interpreted as excellent if greater than 0.75 and as fair to good if between 0.40 and 0.75 . Values below 0.40 represent poor agreement beyond chance alone (32). The Pearson chi-square or Fisher exact tests were performed and considered significant if the P-values were $\leq 0.05$.

\section{Results}

Table 3 summarizes the results of the medical screening procedures pertaining to CTS. The number of subjects varied slightly across the procedures because of missing data in a small number of cases. The proportion of cases meeting the electrodiagnostic criterion for MM- 0.5 was $17 \%$ for the dominant hand and $12 \%$ for the nondominant hand. With the more conservative criterion of MM$0.8,8 \%$ of the subjects met the criterion for the dominant hand and 5\% for the nondominant hand. All but one subject with MM-0.8 also had an absolute median sensory peak latency greater than 3.7 milliseconds, a value indicating that almost all the persons with an abnormal relative latency also had an absolute sensory latency prolongation of the median nerve.

Table 3 also summarizes the physical examination results. Twenty percent of the subjects had at least 1 positive physical examination finding for CTS in both the dominant and nondominant hands. Of the 4 physical

Table 2. Carpal tunnel syndrome (CTS) definitions from results of symptom surveys, nocturnal observations and hand diagram scores.

\begin{tabular}{|c|c|c|}
\hline Description & Abbreviation & Definition \\
\hline Definition 1a. Wrist, hand, or finger symptoms & WHF Sx & $\begin{array}{l}\text { Numbness, burning, tingling or pain in wrist, hands or fingers lasting } \\
1 \text { week up to } 1 \text { year prior to the survey or occurring on } 3 \text { or more } \\
\text { occasions up to } 1 \text { year prior to the survey }\end{array}$ \\
\hline $\begin{array}{l}\text { Definition 1b. Wrist, hand, or finger symptoms \& } \\
\text { nocturnal symptoms }\end{array}$ & WHF SX \& NOC SX & $\begin{array}{l}\text { Numbness, burning, tingling or pain in the wrist, hands or fingers } \\
\text { lasting } 1 \text { week up to } 1 \text { year prior to the survey or occurring on } 3 \text { or more } \\
\text { occasions up to } 1 \text { year prior to the survey and nocturnal symptoms }\end{array}$ \\
\hline Definition 2a. Current symptoms & Cur Sx & $\begin{array}{l}\text { Current wrist, hand or finger discomfort } \geq 0.9 \text { on a } 0-10 \text { visual } \\
\text { analogue scale }\end{array}$ \\
\hline $\begin{array}{l}\text { Definition } 2 \text { b. Current symptoms \& } \\
\text { nocturnal symptoms }\end{array}$ & Cur Sx \& Noc Sx & $\begin{array}{l}\text { Current wrist, hand or finger discomfort } \geq 0.9 \text { on a } 0-10 \text { visual } \\
\text { analogue scale and nocturnal symptoms }\end{array}$ \\
\hline Definition 3a. Hand diagram scores & Hand Diag & Classic or probable hand diagram score \\
\hline $\begin{array}{l}\text { Definition 3b. Hand diagram scores \& } \\
\text { nocturnal symptoms }\end{array}$ & Hand Diag \& Noc Sx & Classic or probable hand diagram score and nocturnal symptoms \\
\hline
\end{tabular}


examination procedures, the carpal canal compression test was the most often positive (11\% for the dominant hands and $10 \%$ for the nondominant hands), while the Tinel's test resulted in the lowest proportion of positive findings (approximately 3\% for both the dominant and nondominant hands).

Definition 1a (ie, WHF Sx alone in table 2) resulted in the highest proportion of cases, with $37 \%$ for the dominant hand and $29 \%$ for the nondominant hand. (See table 3.) The addition of nocturnal symptoms as in definition $1 b$ (ie, WHF Sx and Noc Sx in table 2) resulted in a substantial reduction in the proportion of cases at $16 \%$ and $11 \%$ for the dominant and nondominant hands, respectively. The extent of reporting current discomfort in the wrist, hands, or fingers as in definition $2 \mathrm{a}$ (ie, Cur Sx in table 2) was considerably lower at $20 \%$ for the dominant hand and $11 \%$ for the nondominant hand. The addition of nocturnal symptoms to this definition (definition $2 b$, Cur Sx and Noc Sx in table 2) reduced the proportion to $10 \%$ and $5 \%$ for the dominant and nondominant hands, respectively. The proportion of cases with a classic or probable hand diagram score as in definition 3 a (ie, Hand Diag in table 2 ) was $13 \%$ for the dominant hand and $11 \%$ for the nondominant hand. With the additional criterion of nocturnal symptoms in definition $3 \mathrm{~b}$ (ie, Hand Diag and Noc Sx in table 2), the proportion of cases was reduced to $6 \%$ for the dominant hand and $5 \%$ for the nondominant hand.

Various CTS case definitions were developed by combining different criteria: symptoms and electrodiagnostic results, symptoms and physical examination findings, and symptoms, electrodiagnostic results and physical examination findings (data not shown). The prevalences of cases based on symptoms and MM-0.5 ranged between $2 \%$ and $7 \%$ for the dominant hands and $2 \%$ and $4 \%$ for the nondominant hands. Not surprisingly, the corresponding results for symptoms and MM- 0.8 were slightly lower. For the symptom definitions and physical examination findings, the proportion of cases ranged from $2 \%$ to $11 \%$ for the dominant hand and between $2 \%$ and $9 \%$ for the nondominant hand. When all three crite ria were combined, fewer than $3 \%$ of all the subjects met any combination of criteria which included symptoms, physical examination findings, and electrodiagnostic results.

Figure 1 displays a Venn diagram for CTS in the dominant hand based on wrist, hand, and finger symptoms (WHF Sx in table 2), physical examination findings, and MM-0.5. The overlap between WHF Sx (see table 2), physical examination findings, and MM- 0.5 was poor. Of the 820 subjects, $449(55 \%)$ had at least 1 positive result potentially consistent with CTS [positive WHF Sx (table 2), physical examination finding, or MM-0.5]. Of those with at least 1 positive finding, $67 \%$ had symptoms consistent with CTS, 37\% had positive
Table 3. Results of medical screening procedures for carpal tunnel syndrome (CTS).

\begin{tabular}{|c|c|c|c|c|}
\hline \multirow[t]{2}{*}{ Screening test procedure } & \multicolumn{2}{|c|}{ Dominant hand } & \multicolumn{2}{|c|}{ Nondominant hand } \\
\hline & $\begin{array}{l}\text { Subjects } \\
\text { tested } \\
\text { (N) }\end{array}$ & $\begin{array}{l}\text { Subjects } \\
\text { with } \\
\text { findings } \\
\text { (N) }\end{array}$ & $\begin{array}{l}\text { Subjects } \\
\text { tested } \\
\text { (N) }\end{array}$ & $\begin{array}{l}\text { Subjects \%a } \\
\text { with } \\
\text { findings } \\
(\mathrm{N})\end{array}$ \\
\hline
\end{tabular}

\begin{tabular}{|c|c|c|c|c|c|c|}
\hline \multicolumn{7}{|l|}{ Electrodiagnostic results } \\
\hline $\begin{array}{l}\text { MM- } 0.5^{\mathrm{C}} \\
\text { MM- } 0.8^{\mathrm{C}} \\
\text { MM- } 0.8 \text { and median sensory }\end{array}$ & $\begin{array}{r}824 \\
824 \\
y\end{array}$ & $\begin{array}{r}139 \\
63\end{array}$ & $\begin{array}{r}16.9 \\
7.6\end{array}$ & $\begin{array}{l}822 \\
822\end{array}$ & $\begin{array}{r}100 \\
42\end{array}$ & $\begin{array}{r}12.2 \\
5.1\end{array}$ \\
\hline peak latency $>3.7 \mathrm{~ms}$ & 824 & 62 & 7.5 & 822 & 41 & 5.0 \\
\hline \multicolumn{7}{|l|}{ Physical examination findings } \\
\hline $\begin{array}{l}\text { Positive Phalen's sign } \\
\text { Positive Tinel's sign } \\
\text { Positive carpal }\end{array}$ & $\begin{array}{l}820 \\
823\end{array}$ & $\begin{array}{l}60 \\
23\end{array}$ & $\begin{array}{l}7.3 \\
2.8\end{array}$ & $\begin{array}{l}819 \\
822\end{array}$ & $\begin{array}{l}58 \\
24\end{array}$ & $\begin{array}{l}7.1 \\
2.9\end{array}$ \\
\hline $\begin{array}{l}\text { compression test } \\
\text { Abnormal 2-point }\end{array}$ & 821 & 89 & 10.8 & 820 & 81 & 9.9 \\
\hline $\begin{array}{l}\text { discrimination } \\
\text { One or more of the above }\end{array}$ & 824 & 46 & 5.6 & 822 & 54 & 6.6 \\
\hline 4 tests positive & 820 & 165 & 20.1 & 818 & 160 & 19.6 \\
\hline \multicolumn{7}{|l|}{ Symptoms consistent with CTS } \\
\hline $\begin{array}{l}\text { WHF Sx alone } \\
\text { WHF Sx \& Noc Sx } \\
\text { Cur Sx alone } \\
\text { Cur Sx \& Noc Sx } \\
\text { Hand Diag alone } \\
\text { Hand Diag \& Noc Sx }\end{array}$ & $\begin{array}{l}824 \\
824 \\
824 \\
824 \\
824 \\
824\end{array}$ & $\begin{array}{r}305 \\
130 \\
166 \\
80 \\
103 \\
49\end{array}$ & $\begin{array}{r}37.0 \\
15.8 \\
20.2 \\
9.7 \\
12.5 \\
5.9\end{array}$ & $\begin{array}{l}824 \\
824 \\
824 \\
824 \\
824 \\
824\end{array}$ & $\begin{array}{r}239 \\
91 \\
89 \\
38 \\
89 \\
40\end{array}$ & $\begin{array}{r}29.0 \\
11.0 \\
10.8 \\
4.6 \\
10.8 \\
4.9\end{array}$ \\
\hline
\end{tabular}

a Calculated as percentage of subjects for whom data were available. - MM-0.5 $=\geq 0.5 \mathrm{~ms}$ median minus ulnar sensory peak latency in the same wrist.

c MM-0.8 $=\geq 0.8$ ms median minus ulnar sensory peak latency in the same wrist.

d See table 2 for an explanation of the CTS symptom definitions

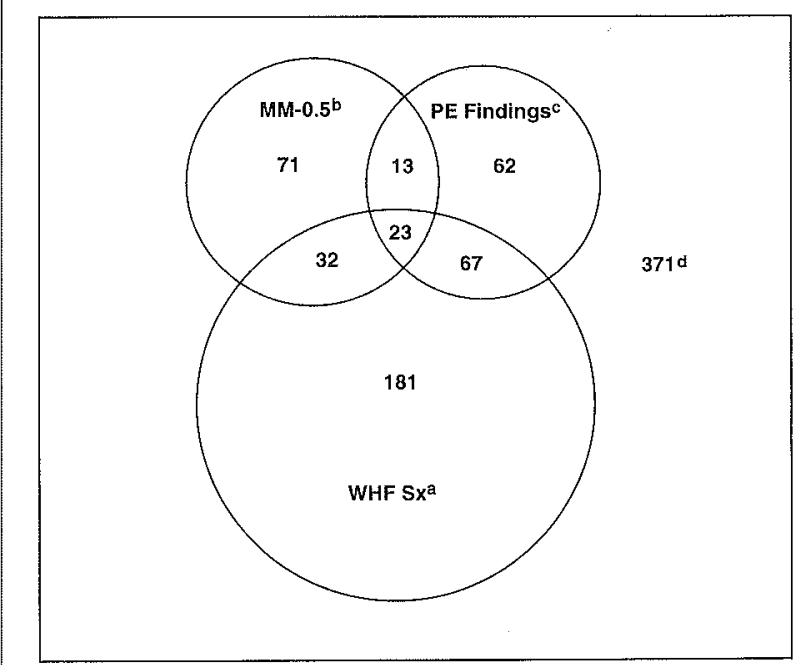

Figure 1. Venn diagram showing the relationship between symptom definition 1a (WHF Sx) ${ }^{\mathrm{a}}, \mathrm{MM}-0.5^{\mathrm{b}}$, and the physical examination finding $\mathrm{S}^{\mathrm{c}}$ consistent with carpal tunnel syndrome (CTS) (dominant hande). ( ${ }^{\text {a see the }}$ text for an explanation of the surveillance symptoms, ${ }^{b} \mathrm{MM}-0.5=\geq 0.5 \mathrm{~ms}$ median minus ulnar sensory peak latency difference in the same wrist, ${ }^{c}$ physical examination considered consistent with CTS if at least 1 of the following were positive: Phalen's test, Tinel's test, carpal compression test or 2-point discrimination test, d represents the number of workers for whom the symptoms, MM- 0.5 , and physical examination findings were all negative, ${ }^{e}$ this diagram was constructed from 820 records having complete symptom, physical examination, and electrodiagnostic test data for the dominant hand) 
physical examination findings, and $31 \%$ had median mononeuropathy (MM-0.5). Overall, 23 out of 449 subjects $(5 \%)$ with at least 1 positive finding met all 3 criteria for the dominant hand. Most of the subjects who reported symptoms potentially consistent with CTS in either hand did not have positive electrical findings or physical examination results suggestive of median nerve compromise at the wrist. Likewise, a clear majority of people with abnormal electrical findings did not report any symptoms potentially consistent with CTS in either hand, and they did not have any physical examination findings suggestive of CTS. In fact, most of the subjects with MM- 0.5 reported no symptoms at all in the corresponding wrists, hands, or fingers (data not shown). This pattern of results was similar regardless of which symptom definition was used, or whether the more conservative electrodiagnostic threshold (MM-0.8) was employed (data not shown).

Table 4 presents the observed and expected values, kappa coefficients, and associated confidence intervals for each symptom criterion alone and also in combination with the physical examination findings in comparison with the MM-0.5. Additional analyses included Pearson chi-square tests to assess the degree of association between the various screening case definitions for CTS and MM-0.5. All the kappa values fell into the poor agreement category ranging between 0.00 and 0.13 . The highest level of agreement was observed between outcomes of hand diagrams alone and MM-0.5 (kappa=0.13, $95 \%$ CI $0.06-0.20$ ). The lowest value was observed between definition $2 \mathrm{~b}$ (Cur Sx \& Noc Sx in table 2) and physical examination findings and MM- 0.5 (kappa $=0.00$,
$95 \%$ CI $-0.05-0.05)$. In general, current symptoms using the 25 th percentile cutoff (discomfort rating $\geq 0.9$ ) showed a low level of agreement with MM- 0.5 with the kappa values ranging between 0.0 and 0.04 when used alone or in combination with nocturnal symptoms or physical examination findings. The use of current symptoms with a higher cutoff point (50th percentile, discomfort rating $\geq 2.1$ ) also showed extremely low kappa values, ranging between 0.00 and 0.03 (data not shown). Similar trends were observed for the level of agreement between procedures in the nondominant hands with kappa values ranging between 0.03 and 0.10 (data not shown).

The chi-square test results listed in table 4 showed a statistically significant association between some of the screening procedures and the MM- 0.5 electrodiagnostic criterion. This relationship was not significant, however, for symptom definition la (WHF Sx in table 2), physical examination findings alone, or symptom definition $1 \mathrm{~b}$ (WHF Sx and Noc Sx) and physical examination findings. All of the CTS definitions which included definition $2 \mathrm{a}$ (Cur Sx in table 2) showed a nonsignificant relationship when compared with MM-0.5, also when the higher cutoff value for current symptoms (discomfort rating 22.1 ) was used and for all the definitions with current symptoms, regardless of the cutoff value for the discomfort rating of the nondominant hand (data not shown).

In almost all the cases the corresponding kappa values were slightly higher, the MM-0.8 electrodiagnostic criterion ranging between 0.04 and 0.18 (data not shown). This range of kappa values still represents poor agreement, however, between the outcomes for CTS.

Table 4. Agreement between screening test procedures for carpal tunnel syndrome (CTS) and median mononeuropathy $(0.5)^{a}$ for the dominant hand.

\begin{tabular}{|c|c|c|c|c|c|c|}
\hline Screening test procedure ${ }^{b}$ & $\begin{array}{l}\text { Observed } \\
\text { agreement } \\
(\%)\end{array}$ & $\begin{array}{c}\text { Expected } \\
\text { agreement } \\
(\%)\end{array}$ & $\begin{array}{c}\text { Kappa } \\
\text { coefficient }\end{array}$ & $\begin{array}{c}95 \% \mathrm{Cl} \\
\text { of kappac }\end{array}$ & $\chi^{20}$ & $\begin{array}{c}\text { P-value } \\
\text { of } \chi^{2}\end{array}$ \\
\hline \multicolumn{7}{|c|}{ Symptoms (Sx) consistent with CTS } \\
\hline $\begin{array}{l}\text { WHF Sx alone } \\
\text { WHF Sx \& Noc Sx } \\
\text { Cur Sx alone } \\
\text { Cur Sx \& Noc Sx } \\
\text { Hand Diag alone } \\
\text { Hand Diag \& Noc Sx }\end{array}$ & $\begin{array}{l}59.5 \\
74.9 \\
70.8 \\
77.6 \\
78.2 \\
81.3\end{array}$ & $\begin{array}{l}58.6 \\
72.7 \\
69.8 \\
76.7 \\
74.9 \\
79.2\end{array}$ & $\begin{array}{l}0.02 \\
0.08 \\
0.03 \\
0.04 \\
0.13 \\
0.10\end{array}$ & $\begin{array}{r}-0.04-0.08 \\
0.01-0.15 \\
-0.04-0.10 \\
-0.03-0.10 \\
0.06-0.20 \\
0.04-0.16\end{array}$ & $\begin{array}{l}0.47 \\
5.36 \\
0.86 \\
1.21 \\
14.7 \\
11.8\end{array}$ & $\begin{array}{r}0.494 \\
0.021 \\
0.35 \\
0.27 \\
<0.001 \\
0.001\end{array}$ \\
\hline \multicolumn{7}{|c|}{ Physical examination (PE) findings } \\
\hline $\begin{array}{l}\text { PE findings alone } \\
\text { WHF Sx \& PE } \\
\text { WHF Sx \& NoC Sx \& PE } \\
\text { Cur Sx \& PE } \\
\text { Cur Sx \& Noc Sx \& PE } \\
\text { Hand Diag \& PE } \\
\text { Hand Diag \& Noc SX \& PE }\end{array}$ & $\begin{array}{l}71.7 \\
77.7 \\
80.4 \\
79.3 \\
80.4 \\
82.1 \\
83.1\end{array}$ & $\begin{array}{l}69.8 \\
75.8 \\
79.3 \\
78.5 \\
80.3 \\
79.8 \\
81.4\end{array}$ & $\begin{array}{l}0.06 \\
0.08 \\
0.05 \\
0.04 \\
0.00 \\
0.11 \\
0.09\end{array}$ & $\begin{array}{r}0.00-0.13 \\
0.01-0.14 \\
-0.01-0.11 \\
-0.02-0.10 \\
-0.05-0.05 \\
0.06-0.17 \\
0.04-0.13\end{array}$ & $\begin{array}{l}3.48 \\
5.32 \\
2.89 \\
1.49 \\
0.01 \\
15.9 \\
15.9\end{array}$ & $\begin{array}{r}0.06 \\
0.021 \\
0.089 \\
0.22 \\
0.91 \\
<0.001 \\
<0.001\end{array}$ \\
\hline
\end{tabular}

a MM-0.5 = $\geq 0.5 \mathrm{~ms}$ median minus ulnar sensory peak latency difference in the same wrist.

${ }^{\circ}$ See table 2 for an explanation of the CTS symptom definitions.

- $95 \%$ confidence interval for $\kappa=\kappa \pm 1.96\left(S E_{\kappa}\right)$

Pearson chi-square test.

\& Represents recurring or lingering wrist, hand, or finger symptoms up to 1 year prior to the survey

f Represents current wrist, hand, or finger discomfort $\geq 0.9$ on a 10 -point visual analogue scale. 


\section{Discussion}

The overall goal of this study was to examine the relationship between symptoms, physical examination findings, and electrodiagnostic test results potentially indicative of CTS in a defined nonclinical population. The overall participation rate of eligible subjects was approximately $75 \%$, which is relatively high, and probably mitigates against significant selection bias. The clinical tools employed in this study, including hand diagrams, physical examination procedures, and sensory nerve conduction tests performed by experienced clinicians, are widely used clinically and in epidemiologic studies of CTS, and they are generally recognized as pertinent to defining the clinical syndrome. Electrodiagnostic findings can also be influenced by other factors, such as obesity, age, height, finger circumference and wrist ratio $(33,34)$. However, the use of the median minus ulnar peak latency difference, as employed in this study, has been shown to be the least sensitive measure to such covariates (35). Moreover, the results are directly applicable to epidemiologic studies of CTS among workers, with minimal, if any, spectrum bias, since the subjects were all active workers in a variety of employment settings that incorporated a broad range of job activities and potential ergonomic exposures (36). Both genders were well represented, and there was a wide range of ages.

Ideally, screening procedures purporting to measure the same outcome should show a high level of agreement (ie, kappa values approaching 1.0) when applied simultaneously across subjects. In this study, however, there was poor agreement between the outcomes of various combinations of symptom surveys, physical examination findings, and electrophysiological testing commonly used for the surveillance and epidemiologic study of CTS. All the kappa values were well below 0.4 , representing poor agreement, or only slightly better than chance alone in many cases. This relationship was consistent regardless of the CTS definition or electrophysiological criterion (MM-0.5 or MM-0.8) used. In most cases, the symptombased definitions, or definitions combining symptoms and physical examination findings, had a statistically significant association with median mononeuropathy. This relationship, however, only held true for recurring or persistent symptoms and not for current symptoms.

While some of the relationships between various symptom-based definitions, or definitions incorporating symptoms and physical examination findings, with electrophysiological test results were statistically significant, it is important to recognize the limitations of such associations and to distinguish the epidemiologic from the clinical implications. The overlap between symptoms consistent with CTS, physical examination findings, and electrodiagnostic results was poor, as noted by figure 1 . Reporting of symptoms consistent with CTS among active workers is common. In this study, however, a majority of the workers ( 248 of 303 or $82 \%$ ) who reported symptoms potentially consistent with CTS did not have electrophysiological abnormalities consistent with CTS in the dominant hand. Of equal significance, most people ( 84 of 139 or $60 \%$ ) with electrophysiological abnormalities did not report symptoms potentially consistent with CTS in the dominant hand. A similar poor overlap was found between symptoms and physical examination findings and also between physical examination findings and electrophysiological test results. These findings were consistent regardless of the CTS definition or electrodiagnostic criterion employed (data not shown). The results were generally weaker for the nondominant hand.

There are several possible explanations for the poor overlap observed between symptoms, physical examination findings, and electrodiagnostic results. Symptoms consistent with CTS (numbness, burning, tingling and pain) may result from stimulation of the median nerve either directly from or secondary to mechanical trauma. The variability between symptoms and electrodiagnostic findings observed in this study suggests that the threshold in symptom production and decreased nerve conduction may vary from person to person. Furthermore, symptom surveys collect information that is subjective in nature and has the potential to be influenced by psychosocial factors (ie, job satisfaction, work organization). The extent to which intersubject variability and psychosocial factors influence symptom development or reporting is unknown. Further research into these issues is therefore warranted.

Another factor contributing to the observed differences between the methodologies concerns the temporal nature of the symptom survey (WHF Sx and Hand Diag in table 2) compared with physical examinations and electrodiagnostic findings. The symptom survey asked subjects to report a symptom if the following conditions were met: the symptom occurred on $\geq 3$ separate occasions in the 12 months preceding the survey or the symptom lasted $>1$ week in the 12 months preceding the survey. Thus the symptom survey reflects findings as much as 1 year prior to the survey, while the results of physical examinations and electrodiagnostic testing reflect findings at the time of the test. It is possible that there are time delays between the development of neural deficits and the subsequent development of symptoms. An alternative explanation is that workers with persistent symptoms may have left the workplace while those with past symptoms (up to 1 year prior) may be in an episodic stage. For example, some workers who are currently symptomatic may also have an abnormal electrodiagnostic test. However, when these same workers are not symptomatic, the electrodiagnostic results may fluctuate.

In order to examine symptoms present at the time of the survey, the subjects were also asked to rate their 
current level of discomfort in the wrist, hands and fingers on a 0 to 10 visual analogue scale. The agreement between current discomfort, positive physical examination results, and electrodiagnostic findings was also poor. This relationship held true regardless of whether a 25 th percentile (discomfort rating $\geq 0.9$ for the dominant hand) or 50 th percentile cutoff (discomfort rating $\geq 2.1$ for the dominant hand) was used. It should be noted that the reported severity of discomfort among this population was relatively low. Part of this poor overlap may be explained by the results found in a recent study in which ratings based on current discomfort showed a high level of instability over time (13). This instability may reflect a change in which the questionnaire is administered or it may represent a true change in the state of the subject's discomfort level. In order to provide a more stable metric for current discomfort, it was suggested that ratings should be averaged over a certain length of time. This same study found that asking subjects to rate their level of discomfort in the last 30 days showed a high level of stability.

It should also be noted that the spectrum and intensity of symptoms associated with CTS may vary and can overlap with a variety of other upper-extremity conditions. The criteria for self-reported symptoms in the present study included numbness, burning, tingling, or pain, whereas, in previous studies using a very similar hand diagram instrument, pain was only admissible as a symptom if it was reported in combination with other symptoms potentially consistent with those used by Katz et al $(6,7)$. In particular, pain can be a very nonspecific symptom, especially if it is experienced in the absence of the other symptoms typically associated with CTS. For these reasons, we re-examined our data to assess the impact of cases who reported only "pain", without reporting numbness, tingling or burning, on the test performance criteria for defining CTS. A small fraction of subjects reported only pain in the wrists, hands or fingers, or were scored as having "classic" or "probable" hand diagrams solely on the basis of pain (eg, 18 of 103 subjects fulfilled symptom definition $2 \mathrm{a}$ (Hand Diag) in the dominant hand based solely on pain). When the agreement was reassessed after such subjects were excluded, there was minimal change in the kappa values. Overall, the inclusion or exclusion of subjects who only reported pain did not make any substantial impact on the findings.

The mechanisms which lead to CTS may suggest another possible explanation for the poor overlap between symptoms and electrodiagnostic findings. Increased pressure within the carpal tunnel may either act mechanically on nerve structures or indirectly on the vasculature, leading to ischemia and subsequent demyelination ( 37 , 38). Previous experimental studies have shown that acute compression on the median nerve resulted in a transient nerve conduction block secondary to ischemia. The compression was associated with reports of symptoms such as numbness and tingling in digits 1 through 4 of the hand and rapidly affected nerve conduction findings and 2- and 3-point discrimination tests $(39,40)$. It is not known how symptoms are expressed if the process of demyelination occurs slowly, such as that occurring from cumulative trauma and localized ischemia. Perhaps, in such instances, prolongation of the median sensory nerve action potential occurs in the absence of a conduction block and without the related symptoms typically seen with "acute" CTS.

The clinical interpretation of electrodiagnostic test results by themselves is somewhat ambiguous since the predictive value of electrodiagnostic test results appears to be low. In a previous study, workers with asymptomatic median mononeuropathy (defined by either MM0.5 or MM-0.8) and an asymptomatic reference group matched for gender, age, and place of employment but with normal median nerve function at the wrists were followed (41). After a mean follow-up period of 17 months, there were no differences in the subsequent development of symptoms potentially consistent with CTS between those with and those without median mononeuropathy. Hence, identification of median mononeuropathy appears to be, at best, a weak predictor of future risk of CTS among asymptomatic workers, and it should not be used as a criterion for excluding workers from jobs.

The results observed in this study appear to be analogous to what has been observed between abnormalities in the lumbar spine and low-back pain. In a recent study, a large number of subjects without low-back pain had evidence of disk abnormalities (ie, bulges or protrusions) in an examination by magnetic resonance imaging (MRI) (42). As a result of this study, and studies with similar findings, the authors caution against using results from MRI examinations of the lumbar spine without considering the rest of the patient's clinical situation (ie, symptoms, mobility, etc). The same cautionary statement can be made as a result of our study. Electrodiagnostic test results should not be interpreted in isolation without taking into account the subject's or patient's symptoms.

Overall, the results are largely consistent with those of previously published studies which have addressed similar issues $(17,19,21-25)$. It should be noted, however, that this study consisted of a worker population, and the outcomes may differ from that of a clinical population. Overall, the electrodiagnostic abnormalities were relatively mild in this study population. For example, with symptoms and MM- 0.5 as criteria, between $2 \%$ and $7 \%$ of the workers in our study had CTS in the dominant hand. In comparison, a $27 \%$ prevalence of CTS was found in a study conducted among a large clinical population (33). In addition, thenar atrophy, often reported in clinical populations, was rarely observed in this group. It is not surprising that a clinical population would have 
a higher prevalence of CTS and more advanced cases than a worker population, as people are more likely to seek treatment when symptoms or impairment has significantly advanced. In addition, after a review of workers' compensation data for Washington State, Franklin et al (43) concluded that intervention typically occurs earlier in work-related cases than in nonwork-related cases (43).

\section{Summary and recommendations}

In summary, the agreement between various combinations of clinical screening procedures and sensory nerve conduction testing was poor. The significance of each test result varied depending on the context in which it was employed. A worker may be most concerned about symptoms, and such concern is often the impetus for seeking help. A clinician may be more concerned about the severity of a physical examination and electrodiagnostic findings in order to determine treatment regimens and evaluate the impact of intervention. The results of this and other studies emphasize the importance of further developing and evaluating methods for the detection of CTS. Until such time, several recommendations for defining CTS within workplace surveillance and epidemiologic studies are provided.

For the surveillance of CTS in the workplace, a discomfort survey, including hand diagrams, is the only procedure that can be recommended for use alone. The results of this study show that none of the test procedures, when used in conjunction with discomfort surveys, demonstrated better agreement than a discomfort survey alone. In fact, many performed much worse. Electrodiagnostic testing by itself is not recommended for surveillance purposes due to the time commitment and high cost of equipment and trained personnel, and also the high proportion of false positive results $(17,19)$.

For research purposes, in the absence of electrodiagnostic testing, a symptom survey based on hand diagrams (with or without consideration of nocturnal occurrence of symptoms) will provide most of the achievable information at a relatively low cost. Investigators may choose to include physical examination procedures, and these may add, at most, a small increment to the positive predictive value, with a concomitant decline in sensitivity (19). However, the potential benefits of physical examination results should be weighed against the additional resources and personnel that must be employed to gather such information.

If electrodiagnostic tests are to be employed for epidemiologic purposes (which we strongly endorse), then it is essential that they be used in conjunction with a symptom survey. This recommendation is based on the findings already noted. Most people with electrodiagnostic findings suggestive of median mononeuropathy have no symptoms, and they do not appear to be at appreciable risk of developing symptoms consistent with CTS. Hence the use of electrodiagnostic test results alone appears to be a poor predictor of symptom development (41). The combination of results from electrodiagnostic testing and symptom survey procedures appears to provide the best criterion for defining CTS for epidemiologic investigations in which the intent is to evaluate either the impact of intervention or the exposure-response relationship (44).

\section{Acknowledgments}

A special acknowledgment is extended to the workers, unions, and managers at the study sites who made this research possible. The authors also wish to thank the residents, nurses, technicians, graduate students, and all others who assisted in the data collection procedures.

This study was funded in part by a grant from the National Institute for Occupational Safety and Health (grant 1 R01 OH02941-01). Its contents are solely the responsibility of the authors and do not necessarily represent the official views of the National Institute for Occupational Safety and Health.

\section{References}

1. Bureau of Labor Statistics. Occupational injuries and illnesses in the United States by industry. Washington (DC): United States Department of Labor, Bureau of Labor Statistics, 1995.

2. Hanrahan LP, Higgins D, Anderson H, Haskins L, Tai S. Project SENSOR: Wisconsin surveillance of occupational carpal tunnel syndrome. Wis Med J 1991;90(2):80,82-3.

3. Hales TR, Bertsche PK. Management of upper extremity cumulative trauma disorders. Am Assoc Occup Health Nurses J 1992;40(3): 118-28.

4. Hagberg M. Exposure variables in ergonomic epidemiology. Am J Ind Med 1992;21:91-100.

5. Hanrahan LP, Moll MB. Injury surveillance. Am J Public Health 1989;79(S):38 - 45.

6. Katz JN, Stirrat CR, Larson MG, Fossel AH, Eaton HM, Liang MH. A self-administered hand symptom diagram for the diagnosis and epidemiologic study of carpal tunnel syndrome. J Rheumatol 1990;17:1495-8.

7. Katz JN, Stirrat CR. A self-administered hand diagram for the diagnosis of carpal tunnel syndrome. J Hand Surg [Am] 1990;15A:360-3.

8. Fine LJ, Silverstein BA, Armstrong TJ, Anderson CA, Sugano DS. Detection of cumulative trauma disorders in the workplace. J Occup Med 1986;28(8):674-8.

9. Silverstein BA, Fine LJ, Armstrong TJ. Hand wrist cumulative trauma disorders in industry. Br J Ind Med 1986;43:779_ 
84.

10. Kuorinka I, Jonsson B, Kilbom A, Vinterberg H, BieringSorensen F, Andersson G, et al. Standardised Nordic questionnaires for the analysis of musculoskeletal symptoms. Appl Ergon 1987; 18(3):233-7.

11. Hales TR, Sauter SL, Peterson MR, Fine LJ, Putz-Anderson $V$, Schleifer LR, et al. Musculoskeletal disorders among visual display terminal workers in a telecommunication company. Ergonomics 1994;37(10):1603-21.

12. Bernard B, Sauter S, Fine L, Petersen M, Hales T. Job task and psychosocial risk factors for work-related musculoskeletal disorders among newspaper employees. Scand J Work Environ Health 1994;20:417-26.

13. Franzblau A, Salerno DF, Armstrong TJ, Werner RA. Testretest reliability of an upper-extremity discomfort questionnaire in an industrial population. Scand J Work Environ Health 1997;23:299-307.

14. Phalen GS. The carpal-tunnel syndrome: seventeen years' experience in diagnosis and treatment of six hundred fiftyfour hands. J Bone Joint Surg [Am] 1966;48A(2):211-28.

15. Mossman SS, Blau JN. Tinel's sign and the carpal tunnel syndrome. Br Med J 1986;294:680.

16. Durkan JA. A new diagnostic test for carpal tunnel syndrome. J Bone Joint Surg 1991;73A(4):535-8.

17. Katz JN, Larson MG, Fossel AH, Liang MH. Validation of a surveillance case definition of carpal tunnel syndrome. Am J Public Health 1991;81(2):189-93.

18. DeKrom MCTFM, Knipschild PG, Kester ADM, Thijs CT, Boekkooi PF, Spaans F. Carpal tunnel syndrome: prevalence in the general population. J Clin Epidemiol 1992;45(4):3736.

19. Franzblau A, Werner R, Valle J, Johnston E. Workplace surveillance for carpal tunnel syndrome: a comparison of methods. J Occup Rehabil 1993;3(1):1-14.

20. Stevens JC. AAEE minimonograph \#26: the electrodiagnosis of carpal tunnel syndrome. Muscle Nerve 1987;10:99-113.

21. Golding DN, Rose DM, Selvarajah K. Clinical tests for carpal tunnel syndrome: an evaluation. $\mathrm{Br} \mathrm{J}$ Rheumatol 1986:25:388-90.

22. DeKrom MCTFM, Knipschild PG, Kester ADM, Spaans F. Efficacy of provocative tests for diagnosis of carpal tunnel syndrome. Lancet 1990;335:393-5.

23. Buch-Jaeger N, Foucher G. Correlation of clinical signs with nerve conduction tests in the diagnosis of carpal tunnel syndrome. J Hand Surg [Br] 1994;19B(6):720—4.

24. Seror P. Sensitivity of the various tests for the diagnosis of carpal tunnel syndrome. J Hand Surg [Br] 1994;19B(6):7258.

25. Gerr F, Letz R. The sensitivity and specificity of tests for carpal tunnel syndrome vary with the comparison subjects. J Hand Surg [Br] 1998;23B(2): 151-5.

26. Denys EH. AAEM minimonograph \#14: the influence of temperature in clinical neurophysiology. Muscle Nerve 1991;9:795-811.

27. Salerno DS. Reliability of nerve conduction studies. In: validity and reliability of health measures for upper extremity conditions among keyboard operators [dissertation]. Ann Arbor (MI): University of Michigan, 1998

28 Kimura J. Electrodiagnosis in diseases of nerve and muscle: principles and practice. Philadelphia (PA): FA Davis Company, 1989.

29. Franzblau A, Werner RA, Albers JW, Grant CL, Olinski D,
Johnston E. Workplace surveillance for carpal tunnel syndrome using hand diagrams. J Occup Rehabil 1994;4(4):18598.

30. Silverstein BA, Fine LJ. Evaluation of upper extremity and low back cumulative trauma disorders: a screening manual. Ann Arbor (MI): The University of Michigan School of Public Health, 1984.

31. STATA Corporation. STATA Corporation (version 5.0). College Station (TX): STATA Corporation. Copyright 19841997.

32. Fleiss JL. Statistical methods for rates and proportions. New York (NY): John Wiley and Sons, 1981

33. Werner RA, Albers JW, Franzblau A, Armstrong TJ. The relationship between body mass index and the diagnosis of carpal tunnel syndrome. Muscle Nerve 1994;17:632-6.

34. Stetson DS, Silverstein BA, Keyserling W, Wolfe RA, Albers JW. Median sensory distal amplitude and latency: comparisons between non-exposed managerial/professional employees and industrial workers. Am J Ind Med 1993;24(2):17589.

35. Salerno DF, Franzblau A, Werner RA, Bromberg MB, Armstrong TJ, Albers JW. Median and ulnar nerve conduction studies among workers: normative values. Muscle Nerve 1998;8:999-1005.

36. Ransohoff DF, Feinstein AR. Problems of spectrum and bias in evaluating the efficacy of diagnostic tests. $N$ Engl J Med 1978;299:926-30.

37. Armstrong TJ, Buckle P, Fine LJ, Hagberg M, Jonsson B, Kilbom A, et al. A conceptual model for work-related neck and upper-limb musculoskeletal disorders. Scand J Work Environ Health 1993;19:73-84.

38. Rempel D. Musculoskeletal loading and carpal tunnel pressure. In: Gordon SL, Blau JN, Fine LJ, editors. Repetitive motion disorders of the upper extremity. Rosemont (IL): American Academy of Orthopaedic Surgeons, 1995:123-32.

39. Gelberman RH, Hergenroeder PT, Hargens AR, Lundborg GN, Akeson WH. The carpal tunnel syndrome: a study of carpal canal pressures. J Bone Joint Surg [Am] 1981;63$\mathrm{A}(3): 380-3$,

40. Lundborg GN, Gelberman RH, Minteer-Convery M, Lee YF, Hargens AR. Median nerve compression in the carpal tunnelfunctional response to experimentally induced controlled pressure. J Hand Surg [Am] 1982;7(3):252-9.

41. Werner RA, Franzblau A, Albers JW, Buchele H, Armstrong TJ. Use of screening nerve conduction studies for predicting future carpal tunnel syndrome. Occup Environ Med $1997 ; 54: 96-100$.

42. Jensen MC, Brant-Zawadzki MN, Obuchowski N, Modic MT, Malkasian D, Ross JS. Magnetic resonance imaging of the lumbar spine in people without back pain. N Engl J Med 1994;331(2):69_73.

43. Franklin GM, Haug J, Heyer N, Checkoway H, Peck N. Occupational carpal tunnel syndrome in Washington State, 19841988. Am J Public Health 1991;81(6):741-6.

44. Erdil M, Mauer KF, Dickerson OB. Carpal tunnel syndrome: diagnosis and case definitions. In: Erdil M, Dickerson OB, editors. Cumulative trauma disorders: prevention, evaluation and treatment. New York (NY): Van Nostrand Reinhold, 1997:3-22.

Received for publication: 27 March 1998 